\title{
This time
}

\author{
With a new administration and pending increases in scientific funding, chemical biologists in the United States have an \\ unprecedented opportunity to influence the national scientific agenda.
}

$T^{\text {h }}$ he inaugural promise of President Barack Obama to "restore science to its rightful place" comes as welcome news to the scientific community in the United States. The president's appointment of bright and capable scientists to leadership positions within the administration, and his apparent willingness to listen to them, offer assurances that scientific voices and rational arguments will inform the government's future decisions. At this critical time, chemical biologists need to forge a scientific agenda that will ensure the ongoing vitality of research at the interface of chemistry and biology.

Last September, we discussed the challenges facing chemical biologists seeking financial support for their interdisciplinary research (Nat. Chem. Biol. 4, 509, 2008). These challenges have only intensified since then, as the collapse of the global financial system has strained governmental budgets, drained private foundation coffers and contracted university endowments. Faculty hiring has been suspended across academia, and even the wealthiest universities have slowed major construction projects (Science 323, 1157, 2009). All of these factors contribute to a grim outlook for academic science in the United States.

Passage of the American Recovery and Reinvestment Act is at least partially offsetting these financial challenges by short-term expansion of the budgets of the federal agencies that fund scientific research (Nature 457, 942-945, 2009). These appropriations, which are to be spent by the end of the third quarter of 2010, represent a substantial investment in American science. The National Institutes of Health $(\mathrm{NIH})$ received $\$ 10$ billion. The National Science Foundation (NSF) was allotted \$3 billion, representing nearly a $50 \%$ increase over its current budgetary levels. The Department of Energy (DOE) received the largest windfall of approximately $\$ 40$ billion, which nearly doubled its 2008 budget. In addition to boosting funding for research grants, these allocations also support research infrastructure, revitalization of current programs and the expansion of grant awards for new equipment and instrumentation.

To complement this short-term strategy, the United States needs a broader scientific funding plan that will create sustainable scientific growth. In late February, the Obama administration put forth its 2010 budget, which proposes a doubling of scientific research funding over the next ten years, a renewed focus on cancer research and targeted programs to support "high-risk research" that will "revolutionize fields of science, and lead to radically new technologies" (Jumpstarting the Economy and Investing for the Future, http://www.whitehouse.gov/omb). The budget also triples fellowship support for science graduate students.

Taken together, the stimulus plan and the 2010 budget proposal are positive first steps in revitalizing science in the United States and are likely to benefit chemical biologists directly. Expanded short-term budgets at the NIH and NSF, two primary funders of chemical biology research, will permit these agencies to fund meritorious proposals that were previously declined due to budget shortfalls and to offer supplements for current awards. Future investments will provide agencies with the necessary flexibility to fund more high-risk projects. Expansion of funding for the NIH Roadmap for Medical Research (http://nihroadmap.nih.gov), specifically the Molecular Libraries and Imaging initiative and the Building Blocks, Biological Pathways and Networks initiative, would significantly enhance chemical biology research. The NIH stimulus package places $\$ 800$ million in the hands of the NIH director. Some of these resources should be used to expand the scope of these programs, particularly the Molecular Libraries Roadmap and PubChem. For some time, we have been calling for greater resourcing for staff and infrastructure (Nat. Chem. Biol. 3, $433,2007)$, which will support expanded curation of the chemical and bioassay information in the PubChem database and the development of improved chemi- and bioinformatic tools. In another area, chemical biologists have been exploring how the tools of chemistry can be combined with the remarkable energy systems in biology to create renewable energy technologies. For the first time, national and scientific interests in energy research have converged in fiscal policy at the DOE. Chemical biologists are likely to become major contributors to future energy research.

Though we welcome scientific expansion, the current enthusiasm needs to be balanced by thoughtful decisions and shared responsibility. First, we need to make certain that the expansion is well managed: grant administrators and scientists need to exercise oversight to ensure that funding decisions are fair, distributed across scientific areas and subject to the scientific rigor that underpins our merit-based funding system (Nature 457, 649, 2009). To ensure ongoing communication between scientists and the federal government, policy makers will need to institute new systems to solicit input from and provide feedback to the scientific community. We further need to ensure that scientists have time to spend on science, so we need to streamline funding mechanisms and reduce unnecessary burdens to applicants and evaluating committees. Second, to prevent the type of boom and bust cycle we saw at the end of the last NIH budget expansion, future scientific growth must be sustainable and matched with projected human and financial resources. In this context, we need to think carefully about how to balance large-scale targeted funding initiatives (for example, the NIH Roadmap) with more traditional investigator-driven awards. Third, we support recent assessments (Science 323, 983 and 1147,2009) that interdisciplinary science, including chemical biology, will be the engine for future scientific discovery and technological advancement. Funding agencies and universities need to provide expanded support for interdisciplinary research and educational programs that will train future leaders of emerging fields.

Chemical biology is at a critical point in its evolution. We also have entered an exciting period where scientific opinions have great potential to influence public policy. The new administration has indicated a willingness to listen to scientists, and chemical biologists need to seize this opportunity to craft a cohesive scientific agenda that will best advance the research and educational priorities of science at the chemistry-biology interface. 